\title{
Gynaecomastia and extragonadal symptoms leading to diagnosis delay of germ cell tumours in young men
}

\author{
Brian M. J. Cantwell, Paul G.G. Richardson and Susan J. Campbell \\ University Department of Clinical Oncology, Regional Radiotherapy Centre, Newcastle General Hospital, \\ Newcastle upon Tyne NE4 6BE, UK
}

\begin{abstract}
Summary: We report two young men with gynaecomastia in whom the underlying causative metastatic germ cell malignancies were not diagnosed for prolonged time periods. Despite the fact that cancer is an uncommon cause of gynaecomastia, doctors should consider germ cell malignancy, even in the absence of testicular symptoms or signs, in previously healthy young men with recent gynaecomastia or other unusual symptoms or signs. Serum beta human chorionic gonadotrophin and other germ cell malignancy markers (alpha fetoprotein and lactic dehydrogenase) should always be assayed. If a testicular primary site is not clinically apparent, there should be early recourse to scrotal ultrasonography.
\end{abstract}

\section{Introduction}

Currently, most men with germ cell tumours can be cured with cisplatin-containing combination chemotherapy, yet the diagnosis is often delayed. ${ }^{1}$ Cure rates could be improved and morbidity decreased (less treatment required) if patients were diagnosed earlier. ${ }^{2}$ The Medical Research Council working party on testicular tumours has determined, in a study of 458 patients with metastatic non-seminomatous germ-cell testicular tumours, that delay from first symptom to start of chemotherapy was related to tumour volume, marker levels and survival and thus delay in starting chemotherapy was a potentially reversible determinant of long-term survival. ${ }^{3}$ We report two patients with gynaecomastia in whom underlying causative germ cell tumours remained undiagnosed for prolonged periods.

\section{Case reports}

\section{Case 1}

A 23 year old man noticed bilateral unequal gynaecomastia in February 1988. He was referred to a hospital consultant, but the patient decided against reduction mammoplasty. Four months

Correspondence: B.M.J. Cantwell, M.D., M.R.C.P., F.R.C.P.I.

Accepted: 21 February 1991 later he developed low back-pain which progressively worsened and two months thereafter he developed haemoptysis which led to a series of investigations culminating in the diagnosis of metastatic malignant trophoblastic teratoma, with para-aortic, pulmonary and hepatic metastases. Serum beta-subunit of human chorionic gonadotrophin (beta HCG) was $196000 \mathrm{IU} / 1$ (normal $<20$ ) and alpha fetoprotein (AFP) was $999 \mathrm{KU} / 1$ (normal $<10$ ). The diagnosis was definitely established 8 months from the onset of gynaecomastia. The patient could not recall any prior testicular abnormalities and there was no testicular abnormality on clinical examination. Testicular ultrasonography, however, showed a small echogenic focus in the upper pole of the right testis, suggesting a regressed primary tumour. Intensive cisplatincontaining combination chemotherapy initially led to tumour shrinkage, but cytotoxic drug resistance developed and progression of metastases occurred. Despite multiple cytotoxic drug therapy the patient died in August 1989. Autopsy was not performed.

\section{Case 2}

A 28 year old man developed a mildy painful swelling of his left testis in May 1989. His family doctor diagnosed a small hydrocele with thickening of the spermatic cord. The patient also wanted a vasectomy so he was referred to a local hospital where a vasectomy was performed a few weeks later. After this the left testicular swelling lessened greatly, but the testis did not, in the patient's view, 
return to normal. Five months later left painful gynaecomastia developed and the patient was again referred to the local hospital for excision of the breast mass under the care of a consultant surgeon. Two months later right gynaecomastia was apparent. The following month dyspnoea and malaise with severe varicella infection developed. In March 1990 the patient was thought to have 'Yuppie flu', but a chest X-ray was arranged by his family doctor and this showed a massive anterior mediastinal mass with separate discreet pulmonary metastases. In the interval, however, the patient collapsed with severe dyspnoea following a game of cricket and required emergency hospital admission. Mediastinoscopy resulted in profuse tumour bleeding and a median sternotomy was required to control haemorrhage. Serum beta HCG was $430000 \mathrm{IU} / 1$ and AFP was within the normal range. Pathological examination of biopsies of the mediastinal mass showed malignant trophoblastic teratoma with strong immunochemical staining for beta $\mathrm{HCG}$ in tumour tissue. Investigations revealed that, in addition to the mediastinal mass, the patient had multiple pulmonary metastases and he also had extensive para-aortic and retrocrural lymph node metastases. There was a very small palpable mass in the left testis and ultrasonography showed an abnormal $5 \mathrm{~mm}$ area, associated with calcification in the left testis, suggesting a regressed primary tumour. The diagnosis was definitely established one year after first testicular symptoms and 8 months after the detection of gynaecomastia. Intensive and prolonged cisplatin-based combination chemotherapy which was associated with much toxicity was given with resultant tumour shrinkage and ultimately fall to normal in serum beta HCG levels. Complete resolution of tumour was pathologically confirmed by laparotomy and thoracotomy after completion of chemotherapy and the patient is now considered cured.

\section{Discussion}

In both cases very high levels of beta HCG were the dominant tumour marker and were the likely cause of the gynaecomastia. In both instances the underlying metastatic malignancy remained undiagnosed for prolonged periods, despite both patients seeing a succession of doctors, including a number of hospital consultants. We have previously shown that the extragonadal symptom of back-pain due to para-aortic node metastases led to significant delay in diagnosis of testicular germ cell tumours by comparison with patients presenting with primary testicular symptoms. ${ }^{4}$ In our previous series 2 out of 9 patients with back pain did not have unilateral testicular swelling at diagnosis, but both gave a history of prior transient painful testicular swelling and at diagnosis both had abnormalities on testicular ultrasonography, suggesting regressed primary testicular tumours. ${ }^{4}$ The first patient with gynaecomastia reported here lacked unilateral testicular swelling at diagnosis, although the second patient had previous painful unilateral testicular enlargement, the true nature of which was unrecognized, even at the time of vasectomy. However, associations between testicular tumours and vasectomy have been reported. ${ }^{5,6}$

These two cases illustrate the importance of a high index of suspicion of an underlying testicular beta-HCG secreting germ cell tumour in young men with gynaecomastia. Delay in diagnosis will lead to increased tumour burden at initiation of chemotherapy and consequently treatment will be less likely to be successful because of the development of cytotoxic resistance, ${ }^{7}$ as occurred in our first reported case.

Gynaecomastia is due to increased oestrogen secretion or to a decreased androgen-oestrogen ratio and germ cell beta-HCG-producing tumours stimulate oestrogen production from the uninvolved areas of the testes. ${ }^{8,9}$ Furthermore enzymatic aromatase activity may be high in malignant trophoblastic tissue and might represent an additional source of oestrogens through conversion from circulating androgens. ${ }^{8}$

Gynaecomastia may be due to a multiplicity of causes which could alter steroid hormone balances and physiological adolescent gynaecomastia with a median age of onset of 15 years is probably its commonest manifestation. ${ }^{8}$ This benign, selflimiting variety of gynaecomastia has usually gone by age 20 but can persist for longer. ${ }^{8}$ It is therefore not surprising that the much rarer pathological gynaecomastia due to germ cell malignancy may be initially mistaken for the physiological variety. However, germ cell tumours should be considered in the differential diagnosis of gynaecomastia in men, as the consequences of missed or delayed diagnosis can be disastrous. This is particularly important nowadays since nearly all patients with small amounts of metastatic germ cell cancer can be cured by early treatment with chemotherapy.

Young men with gynaecomastia should have testicular examinations, repeatedly if necessary, and be carefully questioned about past testicular abnormalities. Serum beta-HCG, AFP and lactic dehydrogenase (which may function as a marker of malignant seminomatous elements) should be determined. Abdominal and chest scan techniques and/or radiology and ultimately biopsy with examination of cell morphology and immunochemical staining for beta-HCG and AFP in tumour tissue will be needed for a definite diagnosis. ${ }^{4}$ In patients without unilateral testicular enlargement the diagnosis may be particularly difficult and the early application of testicular 
ultrasonography could help in establishing the diagnosis. ${ }^{10}$ In young men with gynaecomastia, testicular ultrasonography may also help diagnose other types of testicular tumours. ${ }^{11}$

\section{References}

1. Mead, G.M. Germ cell tumours in men: diagnosis of these cancers is often delayed. Br Med J 1988, 297: 1283-1284.

2. Jones, W.G. \& Appleyard, I. Delay in diagnosing testicular tumours. Br Med J 1985, 290: 1550.

3. MRC Working Party on Testicular Tumours. Prognostic factors in advanced non-seminomatous germ cell testicular tumours: results of a multicentre study. Lancet 1985, i: 8-11.

4. Cantwell, B.M.J., Mannix, K.A. \& Harris, A.L. Back pain - a presentation of metastatic testicular germ cell tumours. Lancet 1987, i: 262-264.

5. Thornhill, J.A., Butler, M. \& Fitzpatrick, J.M. Could vasectomy accelerate testicular cancer? The importance of prevasectomy examination. Br J Urol 1987, 59: 367.

6. Cale, A.R.J., Farouk, M., Prescott, R.J. \& Wallace, I.W.J. Does vasectomy accelerate testicular tumour? Importance of testicular examinations before and after vasectomy. $\mathrm{Br}$ Med J 1990, 300: 370 .

7. Newlands, E.S., Begent, R.H.J., Kaye, S.B., Rustin, G.J.S. \& Bagshawe, K.D. Chemotherapy of advanced malignant teratomas. Br J Cancer 1980, 42: 378-384.

8. Wilson, J.D., Aiman, J. \& Macdonald, P.C. The pathogenesis of gynaecomastia. Adv Intern Med 1980, 25: 1-32.

9. Morrish, D.W., Venner, P.M., Siy, O., Barron, G., Bhardwaj, D. \& Outhet, D. Mechanisms of endocrine dysfunction in patients with testicular cancer. J Natl Cancer Inst 1990, 82: 412-418.

10. Csapo, Z., Bornhof, C. \& Giedl, J. Impalpable testicular tumours diagnosed by ultrasonography. Urology 1988, 33: 549-552.

11. Conway, G.S., MacConnell, T., Wells, G. \& Slater, S.D. Importance of scrotal ultrasonography in gynaecomastia. Br Med J 1988, 297: 1176-1177. 